\title{
Contemporary surgical devices for male stress urinary incontinence: a review of technological advances in current continence surgery
}

\author{
Eric Chung ${ }^{1,2}$ \\ ${ }^{1}$ Department of Urology, Princess Alexandra Hospital, University of Queensland, Brisbane QLD, Australia; ${ }^{2}$ AndroUrology Centre, St Andrew's War \\ Memorial Hospital, Brisbane QLD, Australia \\ Correspondence to: Eric Chung. Associate Professor, AndroUrology Centre, St Andrew's War Memorial Hospital, Boundary St, Brisbane QLD 4000, \\ Australia. Email: ericchg@hotmail.com.
}

\begin{abstract}
Male stress urinary incontinence (SUI) remains a debilitating condition that adversely impacts all domains of quality of life and is associated with significant social stigma and health economic burden. The incidence of post-prostatectomy urinary incontinence (PPI) depends on the definition of urinary incontinence and the length of patient follow up. In patients with persistent PPI following failure of conservative measures, surgical treatment is recommended although there is no published guideline on when surgery should be performed, and what the best surgical option is. Male slings (MS) can be divided into adjustable or non-adjustable types, and offers an attractive option for patients who wish to avoid mechanical handling during urinary voiding. Published intermediate data supports good safety and efficacy rate in men with mild to moderate degree of SUI. The AMS 800 artificial urinary sphincter (AUS) remains the standard of treatment for complete continence and has the longest efficacy and safety records. Other AUS-like devices are designed to address current AMS 800 limitations but themselves are fraught with their own issues.
\end{abstract}

Keywords: Urinary incontinence; post-prostatectomy; surgical device; technology

Submitted Jan 03, 2017. Accepted for publication Mar 26, 2017.

doi: 10.21037/tau.2017.04.12

View this article at: http://dx.doi.org/10.21037/tau.2017.04.12

\section{Introduction}

Stress urinary incontinence (SUI) is defined as involuntary leakage of urine on effort or exertion, or on sneezing or coughing (1). While the incidence of female SUI far outnumbers that of the opposite sex, male SUI is increasingly becoming a common condition especially following radical prostatectomy and can occur in upwards of $60 \%$ of men in the first few months following surgery (2). With an increase in prostate cancer awareness with PSA testing and widespread adoption of robotic-assisted radical prostatectomy as a minimally invasive surgery, it is likely that more men diagnosed with prostate cancer will undergo surgical intervention resulting in higher incidence of postprostatectomy urinary incontinence (PPI). The reported rate of PPI is dependent upon the exact definition of SUI, patient-self reporting and length of follow-up (3). Although most cases of PPI usually resolve within months following vigilant pelvic floor physiotherapy, it is estimated that approximately $5-10 \%$ of men continue to experience PPI at 12 months postoperatively $(4,5)$. In these men, PPI remains a debilitating condition that adversely impacts on all domains of quality of life and is associated with significant social stigma and health economic burden (6).

In patients with persistent PPI following failure of conservative measures, surgical treatment is recommended although there is no published guideline on when surgical treatment should be performed in the postoperative setting. Furthermore, there is no accepted formal definition of the degree of PPI and the choice of surgical treatment, although most experts agree that men with mild to moderate PPI should receive male sling (MS) while men with severe PPI will need artificial urinary sphincter 

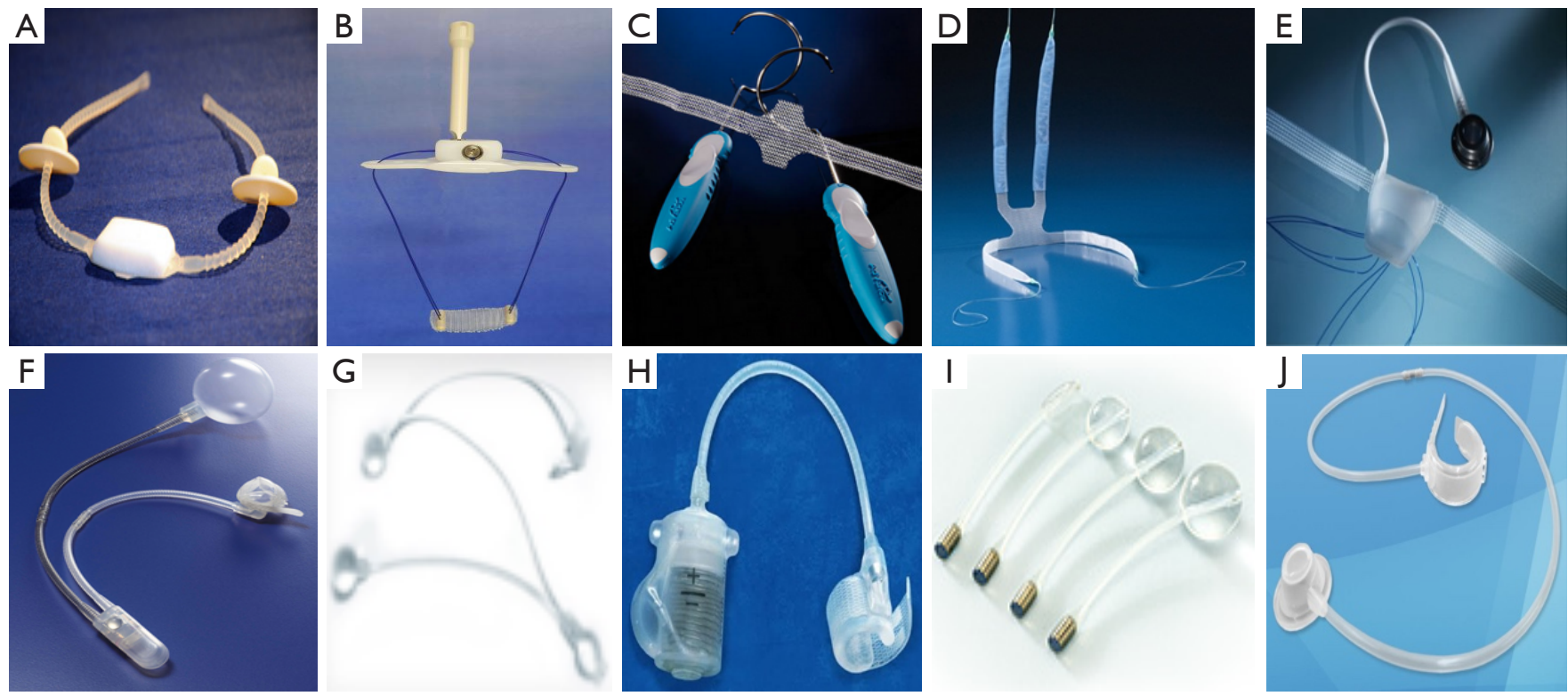

Figure 1 Various male slings (MS) and artificial urinary sphincter (AUS) devices. (A) Argus sling; (B) Remeex sling; (C) Advance sling; (D) Virtue sling; (E) ATOMS sling; (F) AMS 800; (G) FlowSecure sphincter; (H) Zephyr ZSI 375; (I) Pro-ACT device; (J) Periurethral constrictor device.

(AUS) implantation (Figure 1) (7-9). Over the last decade, a plethora of minimal invasive treatment options for male SUI have been developed (7-9). While synthetic MS can be effective in many men with PPI, the AUS has shown consistent and excellent clinical outcomes and to date, remains the benchmark in the treatment for PPI $(8,9)$. The following article examines the technological advances in surgical devices for male PPI.

\section{Methods}

A comprehensive review of all relevant publications pertaining to male continence surgery, prostate cancer treatment, MS and AUS devices were undertaken. A detailed description of surgical techniques and revision of complications related to continence surgery were excluded in this review.

\section{Male slings (MS)}

In recent times, synthetic MS for PPI has gained significant popularity because of its lower cost, less invasive nature and the avoidance of the need for mechanical manipulation when voiding. Most experts agree that proper patient selection is paramount for successful MS outcomes (9). The ideal candidate should have mild to moderate degree of SUI with adequate residual sphincter function and is able to generate strong detrusor contraction to overcome the fixed resistance of the sling in order to void.

Although Berry (10) was first to describe MS surgery, it was Kaufman (11) who popularised one of the earlier external compressive device of the bulbar urethra for the treatment of male SUI. Nonetheless Kaufman's urinary device was associated with low success and high complication rates resulting in these slings being abandoned (12).

When given the choice between MS and AUS, most men with PPI opted for less invasive MS over AUS (13). There are several reasons why MS presents an attractive alternative to AUS. From the patient perspective, there is no postoperative waiting period for healing to occur prior to activation of the device. The patient can void without the need to manipulate any device and is able to achieve an instantaneous significant improvement in their continence rates following removal of the catheter postoperatively. With regards to device design, the MS is not a circumferential occluding device; therefore the risk of urethral atrophy and erosion is uncommon when compared to the AUS (13).

The MS can be divided into adjustable or nonadjustable types, and repositioned under the bulbar urethra either through a retropubic or transobturator approach. Commercially available adjustable MS include Argus (Promedon, Cordoba, Argentina), ReMeex (Neomedic, Barcelona, Spain) and ATOMS (AMI, Feldkirch, Austria) 
while the current non-adjustable MS are Advance (Boston Scientific, Minnetonka, USA) and Virtue (Coloplast, Minneapolis, USA) slings. The adjustable MS has a theoretical advantage over non-adjustable MS because the sling can be revised easily to provide further urethral compression in the event of persistent and/or recurrent urinary incontinence without the need for another MS or salvage AUS surgery. Chung reported that more men chose adjustable over non-adjustable MS when given the options despite no significant difference observed in the clinical outcomes and similar patient satisfaction rate (14).

\section{Argus sling}

The Argus (Promedon, Cordoba, Argentina) system was first popularized in 2006 (15) and consists of a silicone foam pad for compression of the bulbar urethra, two silicone columns of multiple conical elements and silicone washers that allow for regulation of the desired tension on the bulbar urethra. The original Argus sling arms are implanted in a retropubic approach while the newer Argus-T arms allows for transobturator sling placement. The Argus sling is tensioned to a recommended maximum intra-operative retrograde leak point pressure of $45 \mathrm{cmH}_{2} \mathrm{O}$, and in the event of persistent or recurrent SUI, the sling can be tightened through a small non-invasive incision and the silicone washers can be readjusted over the silicone arms.

Published continence rate among men with mild to moderate SUI was reported in $65 \%$ of men (16) and a recent study showed a higher continence rate of around $79 \%$ with further adjustment of the sling being required in $39 \%$ of the cases (17). A newer surgical technique utilizing Argus- $T$, as a transobturator approach, showed that it appears to be safe and was associated with at least $60 \%$ continence rate (18). Common postoperative complications for the Argus sling are transient perineal pain (up to $15 \%$ ), and sling explantation from sling infection $(6 \%)$ and/or erosion (13\%) into the urethra, bladder and through the abdominal wall. Salvage surgery with AUS following failed Argus sling appears to be relatively straight forward too (17).

\section{Remeex sling}

The Remeex sling (Neomedic, Barcelona, Spain) is another adjustable sling located under the bulbar urethra and was introduced in 2004 (19). The mesh is connected via two monofilament traction threads to a suprapubic mechanical regulator which is implanted subcutaneously over the abdominal rectus fascia $2 \mathrm{~cm}$ above the pubis. Further adjustment of Remeex sling is performed though an external manipulator.

The reported dry rate in patients with mild to moderate SUI appeared comparable to the Argus sling with results up to $65 \%(20,21)$. However, readjustment of Remeex sling is common and up to $90 \%$ of patients require at least two adjustments to achieve complete urinary continence. The reported complications include intra-operative bladder injuries (up to $11 \%$ ) and explantation of device (up to 12\%) due to device infection and/or urethral erosion. Postoperative perineal pain is also a common complaint.

\section{AdVance sling}

In contrast to other MS, the AdVance sling (Boston Scientific, MN, USA) is thought not to be compressive in nature, rather it repositions the bulbo-membranous urethra and the lax undescended supporting structures of the posterior urethra and sphincteric structure towards the bladder neck by displacing the proximal urethra from a vertical to horizontal plane underneath the membranous urethra; where the force is applied parallel to the urethral lumen (22). Critical success factors for AdVance sling are good mobility of the sphincteric region and a good residual sphincter function (23).

The initial reported success rate for AdVance sling was moderate (24-26), and the dry rate increased further to $90 \%$ in men wearing 1 to 2 pads (27). Radiotherapy, bulking agents, prior TURP, failed stem cell therapy, previous AUS placement and urethral fibrosis are all compromising factors. In patients who have received radiation therapy, the success rate decreased to $35 \%(28,29)$. More recent multicentre study with intermediate term follow up at 36 months showed $66 \%$ of the patients were cured and $23.4 \%$ reported improvement (30). Major postoperative complications include transient urinary retention requiring temporary re-catheterization, local wound infection, perineal pain and inner thigh sensory numbness. The risk of explantation for the AdVance sling is relatively low (31).

In patients with failed AdVance sling, the implantation of a second AdVance sling has demonstrated relatively good results with more than a third of patient requiring no pad (32). The role of Advance sling as salvage continence surgery following recurrence of SUI with failed transobturator sling showed an overall success rate of $56 \%$, and $39 \%$ of patients were dry after 17.5 months of follow-up (33). Failure of AdVance sling can also be salvaged with AUS or prostate adjustable continence therapy (34). Similarly, men who suffer from recurrent urinary incontinence secondary to cuff compression atrophy can be made continent by the placement of a male sling and 
by not revising the AUS device (35). The advantages of using AdVance to salvage recurrent SUI in AUS patients are the lower risk of postoperative infection due to non-violation of AUS pseudo-capsule and the potential that the patient may not need to rely upon the use of his AUS to maintain continence.

\section{Virtue sling}

The Virtue sling (Coloplast, Minneapolis, UK) was introduced in early 2009. This quadratic ventral elevation urethral sling consists of monofilament polypropylene mesh with four mesh arms, two (inside-out) transobturator arms and two (outside-in) prepubic arms. While the proposed mechanisms of action include ventral urethral elevation from the transobturator arms and distal urethral compression from the prepubic arms (36), the reality is this quadratic sling works similarly to the InVance sling mechanism of action i.e., direct urethral compression against pubic bone. The initial outcome from Virtue sling placement was associated with significant procedure failure and complication rate (37). Following lower anticipated success rate, the surgical technique on Virtue sling placement was updated in early 2010s with proposed tensioning of the transobturator arm laterally to elevate the bulbous urethra and the prepubic arms superiorly similarly to compress the bulbous urethra. The bulbospongiosus muscle is preserved and the quadratic mesh overlies the mid to proximal bulbous urethra. The retrograde leak point pressure system is completed intraoperatively at $60 \mathrm{~cm}$ water pressure closure to visualize compression of the urethra as prepubic arms are tensioned and fixated with a nonabsorbable suture (38). Transobturator and prepubic components of the quadratic fixation contributed to increased urethral resistance as measured by intraoperative retrograde leak point pressure (39). In a recently published multinational clinical trial, Virtue "2" sling with fixation method improved the initial success rate of $42.9 \%$ to $79.2 \%$ in the cohort (40).

In revision or salvage surgery, imbricating non-absorbable sutures can be placed into the dense fibrous mesh and tied down onto the bulbospongiosus muscle, with further tensioning based on retrograde leak point pressure of $60 \mathrm{~cm}$ water pressure (41). The potential adverse events include wound infection, perineal pain and urinary retention.

\section{ATOMS sling}

The adjustable transobturator male system (ATOMS) sling (A.M.I. GmbH, Feldkirch, Austria) is an adjustable sling that has similar components and works on a similar principle to that of the AUS, but with two major differences, namely it does not create a circular compression of the urethra, and secondly, it is designed for postoperative adjustment. Similar to the AUS, it is implanted in the region of the bulbar urethra, however the bulbospongiosus is preserved intact as an additional protective layer between the implant and the urethra, the ATOMS implant is secured in place by two mesh arms of the polypropylene, which are drawn on either side through the obturator foramen and then back to the central cushion component of the implant. The arms are then attached to the cushion, creating a firm, 4 points fixation. The implant is connected by a catheter to a titanium port, which is placed in the scrotum, and this allows for adjustment of the system's pressure postoperatively by altering the filling volume of the cushion (42). Published data on ATOMS showed an overall success rate at $84.2 \%$ with $60.5 \%$ cases defined as dry (0-1 pad and less than $15 \mathrm{~mL} / 24$-hour pad test) at a mean follow-up of 16.9 months (43). Reported complications include wound infection, perineal pain, urethral injury and urinary retention.

\section{AUS-like device}

While synthetic MS have a niche in the treatment of mild to moderate PPI, they are not effective in the moderate to severe PPI and high risk groups such as men with past history of radiotherapy, urethral bulking agents, sling infection/erosion, transurethral prostate surgery or urethral fibrosis. The urinary cuff provides a circumferential occlusion to the urethral lumen, resulting in complete mucosal coaptation. Furthermore, the transmission of fluid from an additional reservoir component can potentially increase the pressure in the occluding urethral cuff that simulates a more physiological sphincter action.

\section{AMS 800}

The first AUS-like prototype was developed in 1973 and over the past four decades has evolved into the current AMS 800 device (American Medical Systems, Minnetonka, MN, USA) $(44,45)$. At present, AMS 800 remains the treatment of choice for persistent moderate and severe PPI and is still regarded as the gold standard treatment for male SUI. This device consists of an inflatable occluding cuff, a pressure regulating balloon (PRB) and a control pump. Published literature supports AMS 800 device as a highly durable, effective (up to $90 \%$ ) and safe surgical option in male SUI with high patient satisfaction rate (44-48). Recent consensus among high volume implanters reported that 
AMS 800 implantation remains a highly-specialized surgery with surgical challenges and that careful patient selection and appropriate surgical care remain paramount in optimal surgical outcomes (49).

While AMS 800 is a safe, durable and effective treatment for PPI, there are limitations such as the requirement for manual dexterity to operate the device, a pre-set geometry in the cuff diameter and the inability to alter the cuff pressure and to correct for delayed tissue atrophy without further surgery $(45,46)$. A recent multicentre study found that penoscrotal single-cuff implantation resulted in significantly higher short-term explantation rates compared to perineal single-cuff AUS (19.2\% vs. 8.6\%; $\mathrm{P}=0.019)$ and that postoperative infection rate was significantly higher after double-cuff compared to single-cuff implantation $(6 \% v s$. $13.9 \% ; \mathrm{P}=0.019)$ (50). Revision and explantation rates due to mechanical failure, urethral atrophy, infection, and cuff erosion vary considerably among published studies (46-49,51). The reported reoperation rate for AUS is around a third of the cases, with about $50 \%$ of these cases caused by mechanical complications and $50 \%$ by non-mechanical complications (46-49,51). While the use of the double (tandem) cuff system was introduced to reduce the urethral atrophy and increase continence rate, it is associated with higher complication rates (52). Revisions include replacement of the malfunctioning component, cuff replacement, repositioning or downsizing due to urethral atrophy, and a second tandem cuff or transcorporal cuff placement $(49,51,53,54)$.

\section{Flow Secure device}

The FlowSecure ${ }^{\mathrm{TM}}$ AUS device (Promedon, Argentina) was originally designed by Craggs and colleagues (55) and has changed several manufacturers over the years. This AUS device attempts to address two major weakness of the AMS 800 namely the inability to protect patients against incontinence secondary to sudden increases in intraabdominal pressure, suggesting that the PRB is not always efficient; and to alter the cuff pressure and correct for cuff atrophy without further surgery.

While the FlowSecure device is implanted as a single unit without the need for tubing connections, excess tubing often complicates the implantation process. This one-piece silicone device comes prefilled with $30 \mathrm{~mL}$ of $0.9 \%$ saline and comprises of four parts connected together by silicone connecting tubes-a regulator balloon, a stress relief balloon, a circular occluding urethral cuff and a control pump. The stress relief balloon is placed extraperitoneally and transmits transient intra-abdominal pressure changes to the urethral cuff to increase occlusion pressure (conditional occlusion). The pressure-regulating balloon establishes a basal occlusive pressure and can be altered by the injection or removal of fluid (depending on continence status).

The urethral cuff consists of a pre-molded and adjustable rounded internal surface for homogenous pressure transmission to reduce the risk of potential cuff stress fracture. Although it is specifically designed for a male urethra, urethral circumference of up to $7 \mathrm{~cm}$ may be supported, large enough to accommodate the female bladder neck (56). One of the earlier concerns with the FlowSecure design was the risk of cuff perforation during pressurization but this appeared to have been rectified with the new control pump that features a resistance valve (57).

While a preliminary report on the outcomes of the FlowSecure device was encouraging at a minimum 12 months follow-up with reported 10 -fold decrease in mean daily leakage volume (770.6 to $55.1 \mathrm{~mL}$ ) and an overall improvement in the Continence Index from 54\% to 97\% (57), a recent study on 100 patients with FlowSecure device showed $6 \%$ mechanical failure, $5 \%$ risk of infection and $9 \%$ risk of pump assembly perforation with repeated puncture of the self-sealing port (58).

\section{Zephyr ZSI 375}

The Zephyr ZSI $375^{\mathrm{TM}}$ (Mayor group, Villeurbanne, France) is another one piece, silicone elastomer urinary continence device. Unlike the AMS 800 and FlowSecure devices, it comprises of two components, a circular urethral cuff and a pressure regulating tank placed in the scrotum. The cuff consists of a molded curved silicone rubber and comes in a range of different diameters from 3.75 to $5 \mathrm{~cm}$ and three different pressure ranges-60-70, 70-80 and 90-100 $\mathrm{cmH}_{2} \mathrm{O}$. The pressure regulating tank consists of an activation button, a hydraulic circuit and a compensation pouch. At rest, a piston mechanism, under spring loaded tension, exerts pressure on the fluid in the hydraulic chamber. When the activation button is pressed, the piston descends forcing fluid from the cuff into the hydraulic circuit and the compensation chamber. Auto-inflation of the cuff occurs within 2-3 minutes.

The theoretical advantages of the Zephyr device over the AMS 800 product are that it is possible to adjust the pressure of the device by injecting or removing fluid from the compensating pouch, and the lack of a third component to be placed in the retropubic space thereby decreasing the risk of bladder injury and device migration (59). While the recent published literature reported no intraoperative 
complication, ZSI 375 device implantation was associated with an overall explantation rate of $61.5 \%(60)$. The reported complications include device defects, device infection, persistent pain and urethral erosion.

\section{Adjustable continence therapy (Pro-ACT)}

Pro-ACT device ${ }^{\mathrm{TM}}$ (Uromedia Inc., MN, USA) is another adjustable continence device that consists of two silicone balloons on the proximal end and a titanium port in the distal end. The two balloons are placed trans-perineally under fluoroscopy or trans-rectal ultrasound guided to the level of the urethra-vesical anastomosis bilaterally, and can be inflated or deflated to compress the urethral lumen and provide outlet resistance $(61,62)$. A recent study reported the use of a navigation guidance system to localize the introduction mandrel which was equipped with tracking targets and that there was no significant difference between rigid cystoscopy and retrovision in symmetrical placement of puncture sites for the silicone balloons (63).

The proposed advantages of ProACT device include technical ease of insertion, low morbidity, relatively low cost, the lack of circumferential urethral dissection and the ability to adjust the degree of mechanical compression with a titratable volume injected into the titanium port. Recent literature showed that successful treatment with ProACT was associated with a significant increase of maximum urethral closure pressure (from median 58.0 to $79.0 \mathrm{cmH}_{2} \mathrm{O}$ ) and that increased in static urethral pressure has contributed to the working mechanism of the ProACT device (64).

Earlier published literature on ProACT device (61) showed that there was a substantial improvement in patient continence rate following an average of three balloon volume adjustments. Despite the initial high cure rate, more than a third of patients were dissatisfied with the surgical outcome in the long-term. Early series on ProACT device reported relatively high complications rates such as device infection and revision $(65,66)$ but recent studies have shown that ProACT device to be effective and safe in a select group of patients with moderate degree of SUI $(67,68)$. One study reported that while ProACT device appears to be safe and efficacious in the short term, postoperative readjustment allows for achievement of a short-term continence and in the long-term, the ProACT does not appear to be an ideal device for durable continence and patients' satisfaction with less than $5 \%$ of patient being dry and $45 \%$ of patients remained satisfied with ProACT device at median followup of 57 months (69). Nonetheless it appears that ProACT device may provide some additional benefits for improving continence in case of persistent incontinence after male sling insertion (70). Common complications of ProACT device include balloon migration, pain, infection and recurrent incontinence.

\section{Periurethral constrictor}

The periurethral constrictor continence device (Silimed, Rio de Janeiro, Brazil) was developed by de O Vilar and colleagues specifically to treat paediatric patients with deficient bladder sphincter function (71). It consists of a constrictor cuff linked by a tube to a hydraulically activated self-sealing valve. The cuff is made of a silicone membrane shaped like an open and inflatable ring, with a polyurethanefoam coat on the internal surface and a polyester tissue reinforcement band on the external surface. The external band contains two pairs of buttons and four pairs of holes along its length to allow for adjustment of the device around the bladder neck or the bulbar urethra. The two sections of silicone tubes (200 and $500 \mathrm{~mm}$ long) are joined by a plastic connector linking the valve to the constrictor cuff. The Silimed periurethral contractor device works in a hydraulic manner and can be adjusted through injection of sterile saline into the self-sealing port. It is advocated that the cuff pressure should be relieved for about two months each year to minimize tissue ischemia and subsequent cuff erosion (71). An initial report has demonstrated satisfactory outcome in PPI and that $73.3 \%$ of the patients had functional devices and were socially continent at a mean follow-up of 42.1 months (72). Nonetheless, this device is plagued by high complication rates such as the need to add more fluid in the port to increase the occlusive static pressure of the cuff, urethral erosion, device infection and device malfunction with fluid loss caused by needle perforations in the valve. Recent publication found that Silimed device is not safe with high risk of urethral erosion especially in PPI cohort and that detailed counselling is mandatory when considering the implant in adult patients (73).

Unlike AMS $800^{\mathrm{TM}}$ device, this compressive urinary device is relatively inexpensive and the patient avoids the need to manipulate a pump to void. However, patients are required to void against resistance created by the device and the long-term effects of this mechanical compression on the urethra and upper urinary tract are unknown. While the preliminary outcomes on this periurethral constrictor device are encouraging, larger patient participation and longer term follow-up need to be conducted to address the long-term effectiveness and safety of this urinary device. 


\section{Conclusions}

Male SUI especially PPI is not uncommon and adversely impacts on a patient's quality of life and is associated with significant economic burden. The MS is an attractive alternative for patients who wish to avoid mechanical handling during urinary voiding and intermediate data supports good safety and efficacy rate in men with mild to moderate degree of SUI. Furthermore, published literature supports that MS has lower complications rates than AUS (74). Nonetheless, the AMS 800 device remains the standard of treatment for complete continence and has the longest efficacy and safety records. Other AUS-like devices are designed to address current AMS 800 limitations but themselves are fraught with their own issues.

Newer experimental continence devices need to be innovative in design and to closely simulate a healthy human sphincter and responds adequately to the various external and internal stimuli. Emerging novel therapies such as nanotechnology driven device and stem cell therapy are very attractive but are not currently commercially widely available or have proven long term outcome. Until the emergence of a better engineered urinary device, and/or further achievement in stem cell therapy or tissue engineering, significant challenges remain in the quest for an ideal urinary continence therapy.

\section{Acknowledgements}

None.

\section{Footnote}

Conflicts of Interest: The author has no conflicts of interest to declare.

\section{References}

1. Abrams P, Cardozo L, Fall M, et al. the standardization of terminology of lower urinary tract function: report from the Standardisation Sub-committee of the International Continence Society. Neurourol Urodyn 2002;21:167-78.

2. Kao TC, Cruess DF, Garner D, et al. Multicenter patient self-reporting questionnaire on impotence, incontinence and stricture after radical prostatectomy. J Urol 2000;163:858-64.

3. Krupski TL, Saigal CS, Litwin MS. Variation in continence and potency by definition. J Urol 2003;170:1291-4.
4. Seo HJ, Lee NR, Son SK et al. Comparison of robotassisted radical prostatectomy and open radical prostatectomy outcomes: a systematic review and metaanalysis. Yonsei Med J 2016;57:1165-77.

5. Campbell SE, Glazener CM, Hunter KF, Cody JD, Moore $\mathrm{KN}$. Conservative management for postprostatectomy urinary incontinence. Cochrane Database Syst Rev 2012;1:CD001843.

6. Silva LA, Andriolo RB, Atallah AN, et al. Surgery for stress urinary incontinence due to presumed sphincter deficiency after prostate surgery. Cochrane Database Syst Rev 2014;4:CD008306.

7. Bauer RM, Bastian PJ, Gozzi C, et al. Post-prostatectomy incontinence: All about diagnosis and management. Eur Urol 2009; 55:322-33.

8. Van Bruwaene S, De Ridder D, van der Aa F. The use of sling vs. sphincter in post-prostatectomy urinary incontinence. BJU Int 2015;116:330-42.

9. Bauer RM, Gozzi C, Hubner W, et al. Contemporary management of postprostatectomy incontinence. Eur Urol 2011;59:985-96.

10. Berry J. New procedure for correction of urinary incontinence: a preliminary report. J Urol 1961;85:771-5.

11. Kaufman JJ. Urethral compression operations for the treatment of post-prostatectomy incontinence. J Urol 1973;110:93-6.

12. Durrani AF, Rosenbaum TP, Shaw PJ, et al. Does the Kaufman prosthesis still have a place? Review of thirteen years' experience. Urology 1991;38:328-31.

13. Kumar A, Litt ER, Ballert KN, et al. Artificial urinary sphincter versus male sling for post-prostatectomy incontinence-what do patients choose? J Urol 2009;181:1231-5.

14. Chung E, Smith P, Malone G, et al. Adjustable versus non-adjustable male sling for post-prostatectomy urinary incontinence: A prospective clinical trial comparing patient choice, clinical outcomes and satisfaction rate with a minimum follow up of 24 months. Neurourol Urodyn 2016;35:482-6.

15. Romano SV, Metrebian SE, Vaz F, et al. An adjustable male sling for treating urinary incontinence after prostatectomy: a phase III multicentre trial. BJU Int 2006;97:533-9.

16. Romano SV, Metrebian SE, Vaz F, et al. Long-term results of a phase III multicentre trial of the adjustable male sling for treating urinary incontinence after prostatectomy: minimum 3 years. Actas Urol Esp 2009;33:309-14.

17. Hübner WA, Gallistl H, Rutkowski M, Huber ER. Adjustable bulbourethral sling: experience after 101 cases 
of moderate-to-severe male stress urinary incontinence. BJU Int 2011;107:777-82.

18. Cornel EB. Argus-T adjustable male sling: The influence of surgical technique on complications and short-term efficacy. Urol Int 2016;96:164-70.

19. Sousa-Escandón A, Rodriguez Gomez JI, Uribarri Gonzalez C, et al. Externally readjustable sling for treatment of male stress urinary incontinence: points of technique and preliminary results. J Endourol 2004;18:113-8.

20. Navalón-Monllor V, Ordono-Dominguez F, Pallas-Costa $\mathrm{Y}$, et al. Long-term follow-up for the treatment of male urinary incontinence with the Remeex system. Actas Urol Esp 2016;40:585-91.

21. Sousa-Escandón A, Cabrera J, Mantovani F et al. Adjustable suburethral sling (male Remeex system) in the treatment of male stress urinary incontinence: a multicentric European study. Eur Urol 2007;52:1473-9.

22. Rehder P, Gozzi C. Transobturator sling suspension for male urinary incontinence including post-radical prostatectomy. Eur Urol 2007; 52:860-6.

23. Rehder P, Freiin von Gleissenthall G, Pichler R, et al. The treatment of postprostatectomy incontinence with retroluminal transobturator repositioning sling (Advance): lessons learnt from accumulative experience. Arch Esp Urol 2009;62:860-70.

24. Bauer RM, Mayer ME, Gratzke C, et al. Prospective evaluation of the functional sling suspension for male postprostatectomy stress urinary incontinence: Results after 1 year. Eur Urol 2009;56:928-33.

25. Cornu JN, Sebe P, Ciofu C, et al. The AdVance transobturator male sling for postprostatectomy incontinence: Clinical results of a prospective evaluation after a minimum of 6 months. Eur Urol 2009;56:923-7.

26. Rehder P, Mitterberger MJ, Pichler R, et al. The 1 year outcome of the transobturator retroluminal repositioning sling in the treatment of male stress urinary incontinence. BJU Int 2010;106;1668-72.

27. Gozzi C, Becker AJ, Bauer RM, et al. Early results of transobturator sling suspension for male urinary incontinence following radical prostatectomy. Eur Urol 2008; 54:960-1.

28. Cornu JN, Sebe P, Ciofu C, et al. Mid-term evaluation of the transobturator male sling for post-prostatectomy incontinence: focus on prognostic factors. BJU Int 2011;108:236-40.

29. Bauer RM, Soljanik I, Fullhase C, et al. Results of AdVance transobturator male sling after radical prostatectomy and adjuvant radiotherapy. Urology 2011;77:474-9.

30. Bauer RM, Grabbert MT, Klehr B, et al. 36-month data for the AdVance XP male sling: results of a prospective multicentre study. BJU Int 2017;119:626-30.

31. Bauer RM, Mayer ME, May F, et al. Complications of the AdVance transobturator male sling in the treatment of male stress urinary incontinence. Urology 2010;75:1494-8.

32. Soljanik I, Becker AJ, Stief CG, et al. Repeat retrourethral transobturator sling in the management of recurrent postprostatectomy stress urinary incontinence after failed first male sling. Eur Urol 2010;58:767-72.

33. Martinez EJ, Zuckerman JM, Henderson K, et al. Evaluation of salvage male transobturator sling placement following recurrent stress urinary incontinence after failed transobturator sling. Urology 2015;85:478-82.

34. Al-Najar A, Kaufmann S, Boy S, et al. Management of recurrent post-prostatectomy incontinence after failed previous failed retrourethral male slings. Can Urol Assoc J. 2011;5:107-11.

35. Christine B, Knoll LD. Treatment of recurrent urinary incontinence after artificial urinary sphincter placement using the AdVance male sling. Urology 2010;76:1321-4.

36. Comiter CV, Rhee EY. The "ventral urethral elevation plus" sling: a novel approach to treating stress urinary incontinence in men. BJU Int 2008;101:187-91.

37. McCall AN, Rivera ME, Elliot DS. Long-term follow up of the virtue quadratic male sling. Urology 2016;93:213-6.

38. Rhee E. Placement of quadratic male sling. J Sex Med 2012;9:653-6.

39. Comiter CV, Nitti V, Elliot C, et al. A new quadratic sling for male stress incontinence: retrograde leak point pressure as a measure of urethral resistance. J Urol 2012;187:563-8.

40. Comiter CV, Rhee EY, Tu LM, et al. The Virtue sling- a new quadratic sling for postprostatectomy incontinenceresults of a multinational clinical trial. Urology 2014;84:433-8.

41. Rhee EY. Quadratic male sling revision. J Sex Med 2014;11:4-7.

42. Bauer $W$, Brössner C. Adjustable transobturator male system-ATOMS — for the treatment of postprostatectomy urinary incontinence: The surgical technique. Pelviperineology 2011;30:10-6.

43. Seweryn J, Bauer W, Ponholzer A, et al. Initial experience and results with a new adjustable transobturator male system for the treatment of stress urinary incontinence. J Urol 2012;187:956-61.

44. Chung E. A state of art review on the evolution of the urinary sphincter devices for the treatment of post- 
prostatectomy urinary incontinence: Past, present and future innovations. J Med Eng Technol 2014;38:328-32.

45. Chung E, Ranaweera M, Cartmill R. Newer and novel artificial urinary sphincters (AUS): The development of alternatives to the current AUS device. BJU Int 2012;110:5-11.

46. Elliott DS, Barrett DM. Mayo Clinic long-term analysis of the functional durability of the AMS 800 artificial urinary sphincter: a review of 323 cases. J Urol 1998;159:1206-8.

47. Gousse AE, Madjar S, Lambert MM, et al. Artificial urinary sphincter for post-radical prostatectomy urinary incontinence: long-term subjective results. J Urol 2001;166:1755-8.

48. Kim SP, Sarmast Z, Daignault S, et al. Long-term durability and functional outcomes among patients with artificial urinary sphincters: a 10-year retrospective review from the University of Michigan. J Urol 2008;179:1912-6.

49. Biardeau X, Aharony S, AUS Consensus Group, et al. Artificial urinary sphincter: Report of the 2015 Consensus Conference. Neurourol Urodyn 2016;35 Suppl 2:S8-24.

50. Kretschmer A, Husch T, Thomsen F, et al. Complications and short-term explantation rate following artificial urinary sphincter implantation: Results from a large middle European multi-institutional case series. Urol Int 2016;97:205-11.

51. Chung E, Cartmill R. Diagnostic challenges in the evaluation of persistent or recurrent urinary incontinence after artificial urinary sphincter (AUS) implantation in patients after prostatectomy. BJU Int 2013;112:32-5.

52. O'Connor RC, Lyon MB, Guralnick ML, et al. Longterm follow-up of single versus double artificial urinary sphincter insertion for the treatment of severe prostatectomy stress urinary incontinence. Urology 2008;71:90-3.

53. DiMarco DS, Elliot DS. Tandem cuff artificial urinary sphincter as a salvage procedure following failed primary sphincter placement for the treatment of postprostatectomy incontinence. J Urol 2003;170:1252-4.

54. Guralnick ML, Miller E, Toh KL, et al. Transcorporal artificial urinary sphincter cuff placement in cases requiring revision for erosion and urethral atrophy. J Urol 2002;167:2075-8, discussion 2079.

55. Knight SL, Susser J, Greenwell T, et al. A new artificial urinary sphincter with conditional occlusion for stress urinary incontinence: preliminary clinical results. Eur Urol 2006;50:574-80.

56. García-Montes F, Vicens-Vicens A, Ozonas-Moragues M, et al. Surgical implantation of the new Flow Secure artificial urinary sphincter in the female bladder neck. Urol Int 2007;79:105-10.

57. García-Montes F. FlowSecure artificial urinary sphincter for the treatment of stress urinary incontinence after radical prostatectomy. Arch Esp Urol 2009;62:845-50.

58. Alonso Rodriguez D, Fes Ascanio E, Fernandez Barranco L, et al. One Hundred FlowSecure Artificial Urinary Sphincters (Abstract). Eur Urol Suppl 2011;10:309.

59. Staerman F, G-Llorens C, Leon P, et al. ZSI 375 artificial urinary sphincter for male urinary incontinence: a preliminary study. BJU Int 2013;111:E202-6.

60. Kretschmer A, Husch T, Thomsen F, et al. Efficacy and safety of the ZSI375 artificial urinary sphincter for male stress urinary incontinence: lessons learned. World J Urol 2016;34:1457-63.

61. Hübner WA, Schlarp OM. Treatment of incontinence after prostatectomy using a new minimally invasive device: adjustable continence therapy. BJU Int 2005;96:587-94.

62. Gregori A, Romano AL, Scieri F, et al. Transrectal ultrasound-guided implantation of Adjustable Continence Therapy (ProACT): surgical technique and clinical results after a mean follow-up of 2 years. Eur Urol 2010;57:430-6.

63. Chevrot A, Jaffard A, Medici M, et al. Rigid cystoscopy versus retrovision for adjustable peri-urethral balloons guidance: Comparison of precision thanks to a surgical navigation system. Prog Urol 2016;26:566-72.

64. Reuvers SH, Groen J, Scheepe JR, et al. Maximum urethral closure pressure increases after successful adjustable continence therapy (ProACT) for stress urinary incontinence after radical prostatectomy. Urology 2016;94:188-92.

65. Lebret T, Cour F, Bencherit J, et al. Treatment of postprostatectomy stress urinary incontinence using a minimally invasive adjustable continence balloon device, ProACT: results of a preliminary, multicenter, pilot study. Urology 2008;71:256-60.

66. Gilling PJ, Bell DF, Wilson LC, et al. An adjustable continence therapy for treating incontinence after prostatectomy: a minimum 2-year follow up. BJU Int 2008;102:1426-30, discussion 1430-1.

67. Aboseif SR, Sassani P, Franke EI, et al. Treatment of moderate to severe female stress urinary incontinence with the adjustable continence therapy (ACT) device after failed surgical repair. World J Urol 2011;29:249-53.

68. Aboseif SR, Franke EI, Nash SD, et al. The adjustable continence therapy system for recurrent female stress urinary incontinence: 1-year results of the North America Clinical Study Group. J Urol 2009;181:2187-91. 
69. Venturino L, Dalplaz O, Pummer K, et al. Adjustable continence balloons in men: Adjustments do not translate into long-term continence. Urology 2015;85:1448-52.

70. Yiou R, Butow Z, Baron T, et al. Adjustable continence therapy (ProACT) after male sling failure for patients with post-radical prostatectomy urinary incontinence: a prospective study with one-year follow-up. World J Urol 2015;33:1331-6.

71. de O Vilar F, Araujo LA, Lima SV. Periurethral constrictor in paediatric urology: long-term follow-up. J Urol 2004;171:2626-8.

72. Schiavini JL, Damiao R, Dutra JA, et al. Treatment of

Cite this article as: Chung E. Contemporary surgical devices for male stress urinary incontinence: a review of technological advances in current continence surgery. Transl Androl Urol 2017;6(Suppl 2):S112-S121. doi: 10.21037/tau.2017.04.12 post-operative surgery urinary incontinence with the periurethral constrictor: A retrospective analysis. J Urol 2009;75:1488-92.

73. Favro M, Billia M, Volpe A, et al. Long-term outcomes of the implant of a periurethral constrictor for stress urinary incontinence following radical prostatectomy. Urol Int 2016;97:26-31.

74. Alwaal A, Harris CR, Awad MA, et al. Comparison of complication rates related to male urethral slings and artificial urinary sphincters for urinary incontinence: national multi-institutional analysis of ACS-NSQIP database. Int Urol Nephrol 2016;48:1571-6. 